Editorial

\title{
Improving the observation and prediction capabilities for Arctic marine environment: from the perspective of Arctic Shipping
}

Hui Wang ${ }^{1}$, Qizhen Sun ${ }^{1 *}$, Lin Zhang ${ }^{1}$, Xi Liang ${ }^{1}$, Qinghua Yang ${ }^{2}$, Na Liu ${ }^{1}$, Chunhua Li ${ }^{1}$, Qingsheng Liu ${ }^{3}$, Bingrui $\mathrm{Li}^{4}$, Qian Feng ${ }^{5}$, Xiao Cheng ${ }^{6}$, Yi Yu ${ }^{7}$

${ }^{1}$ National Marine Environmental Forecasting Center, Beijing 100081, China

${ }^{2}$ School of Atmospheric Sciences, Sun Yat-sen University, Zhuhai 519082, China

${ }^{3}$ Institute of Geographic Sciences and Natural Resources Research, Chinese Academy of Science, Beijing 100101, China

${ }^{4}$ Polar Research Institute of China, Shanghai 200136, China

${ }^{5}$ National Satellite Ocean Application Service, Beijing 100081, China

${ }^{6}$ School of Geospatial Engineering and Science, Sun Yat-sen University, Zhuhai 519082, China

${ }^{7}$ Donghai Navigation Safety Administration, Ministry of Transport, Shanghai 200086, China

Received 5 December 2020; accepted 31 December 2020

(c) Chinese Society for Oceanography and Springer-Verlag GmbH Germany, part of Springer Nature 2021

In recent decades, Arctic climate is warming at a rate of almost twice the global average (Osborne et al., 2018). The surface atmosphere and oceanic temperatures over Arctic Ocean increase leads to the rapid retreat of sea ice. The extension and thickness of sea ice in the Arctic, as well as the multi-year ice coverage, have decreased significantly. For example, the September sea ice extent in the Arctic, which is the end of the summer melt season, decreases at a rate of larger than 11\% per decade (Polyakov et al., 2012).

With the rapid shrink of Arctic sea ice, the accessibilities of Arctic sea routes have been enhanced remarkably, and the commercial and large-scale shipping have been preliminarily implemented. The Arctic sea routes consist of the Northeast Passage (NEP) on the Russian side, the Northwest Passage (NWP) on the Canadian side, and the central sea route across the high latitudes of the central Arctic Ocean. Consequently, in the future, the shipping pattern will be greatly changed at the global scale because of widely use of Arctic sea routes. In addition, the climate change in polar regions brings unprecedented opportunities for polar scientific expeditions, shipping, as well as other human activities. Thus, the polar region has received increasing attentions from the international communities.

The use of Arctic sea routes highly relies on the environmental conditions of sea ice, weather, and ocean. The rough weather and sea ice conditions are still the most disadvantageous factors to restrict the utilization of Arctic sea routes. Therefore, their forecasts and applications to navigation support are very important for the development of Arctic shipping (Inoue, 2020). Sea ice, which has a large and complicated spatiotemporal variability (Lei et al., 2015). At present, there is a lack of long-term and continuous observation network for the Arctic marine environment, especially for sea ice, which is a grand challenge for the utilization of the Arctic sea routes. The comprehensive observations of sea ice, atmosphere, and ocean, and the through understanding of interactions among Arctic atmosphere, sea ice, and ocean, as well as the changes in the regimes of the Arctic sea ice formation and decay can help to better understand the complex temporal and spatial changes in Arctic sea ice. It is also particularly urgent to analyze and examine important disastrous weather, such as sea fog and cyclones that affect the Arctic shipping. The expected increased shipment using the Arctic sea routes require more reliable forecasts that provide information about sea ice concentration and thickness, horizontal visibilities, and winds. These needs can only be met by developing and coupling polar-related sea ice and weather models into forecasting systems.

At present, the Arctic has attracted more and more scientific projects launched by international organizations. To effectively cope with the coexistence of opportunities and challenges in polar regions, the community has in recent years strengthened the international cooperation in observation, research, forecasting, and application in the polar regions (e.g., Lawrence et al. 2019). In 2013, the World Meteorological Organization (WMO) World Weather Research Program (WWRP) launched the Polar Prediction Project (PPP). Its goal is to enable a significant improvement in environmental prediction capabilities for the polar regions and beyond, by coordinating a period of intensive observing, modeling, prediction, verification, user-engagement, and education activities (Jung et al., 2016). In 2019-2020, the Alfred-Wegener-Institut Helmholtz-Zentrum für Polar-und Meeresforschung (AWI), German, implemented the huge international project of Multidisciplinary drifting Observatory for the Study of Arctic Climate (MOSAiC). The subjects covered by the MOSAiC plan include atmosphere, sea ice, oceanography, ecology, and biogeochemical cycle (Rex et al., 2017; Krumpen et al., 2020).

In recent years, international researches on the Arctic are gradually shifting from observations and research on basic of polar marine environments to monitoring and determining the environment's responses to Arctic changes, as well as the response strategies on polar change and how to minimize the adverse effects of polar changes. These scientific activities eventually transformed into national interests, such as the delimitation of the continental shelf, hydrocarbon resources. The need to carry out targeted intensive explorations and scientific research is also increasingly urgent. The explorations and research will provide a solid support for

Foundation item: The National Key R\&D Program of China under contract No. 2016YFC1402700.

*Corresponding author, E-mail: sunqizhen@nmefc.cn 
China's participation in the Arctic affairs.

Since the first Chinese National Arctic Research Expedition in 1999, China has dispatched eleven Arctic expeditions. The investigations collected valuable data, which provide the foundation for understanding the weather, climate, and sea ice in the Arctic. In recent years, China has implemented the operation of the Arctic NEP. In the summer of 2013, the merchant vessel "Yongsheng" opened the era for China's commercial using the NEP. By 2019, around 30 commercial ships have passed through the Arctic NEP in summer, and have achieved considerable social and economic benefits.

To meet the increasing requirements for the prediction of activities in the Arctic, China has strengthened the research and development of operational monitoring and forecasting for the development and utilization of the Ice Silk Road (e.g., the Arctic IceOcean Prediction System (ArcIOPS) of National Marine Environmental Forecasting Center (NMEFC); Fig. 1; Mu et al., 2019). Longterm continuous real-time observations of the marine environments in the Arctic Ocean are required. Numerical prediction models for weather, sea ice, and ocean of the Arctic need to be developed, so that short-term forecasts and mid- and long-term predictions can be provided. The polar forecast products need to meet the requirements by scientific surveys and commercial shipping. Remote sensing has demonstrated its unique advantages on Arctic observations, particularly with respect to the sea ice monitoring at the basin scale. Both the optical and microwave sensors have provided abundant information in terms of sea ice extent, concentration and motion, coverage/distribution of leads and melt ponds, and many other key parameters of sea ice. Some related information has been providing operationally for the continuous monitoring in the Arctic. It is foreseen that satellite remote sensing will play more and more important roles in the Arctic environment monitoring, the climatology, and the shipping supporting.

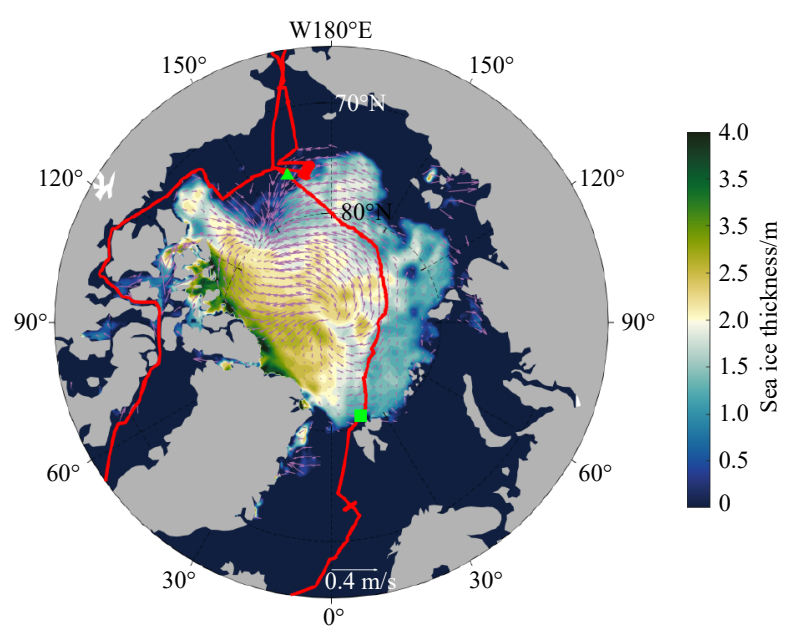

Fig. 1. Sea ice thickness forecasting provided by Arctic Ice-Ocean Prediction System (ArcIOPS) for the 8th Chinese National Arctic Research Expedition (CHINARE). Red solid lines indicate the track of the R/V Xuelong.

The purpose of this special section is to bring together the latest multidisciplinary research on the Arctic climate and sea ice and to provide data monitoring, forecasting, and service for China's commitment to the development of the Ice Silk Road. This special section contains five papers, covering a broad scope of Arctic research topics. Ji et al. (2021) made a comprehensive analysis of sea ice and snow morphology during summer in the Pacific sector of Arctic Ocean. They found that there are lots of areas with low sea ice concentration south of $78^{\circ} \mathrm{N}$, while sea ice concentration and thickness increase with the latitude to north of $78^{\circ} \mathrm{N}$. Qin et al. (2021) retrieved the sea surface wind speed from Sentinel-1 SAR images using conventional retrieval and machine learning methods. Their results are better than those retrieved using the Polarization Ratio models. Chen et al. (2021) cross-calibrated the brightness temperature obtained from FY-3B/MWRI and Aqua/AMSR-E. Using robust linear regression analysis, the slopes, and intercepts of the fitted equations for the brightness temperature can be used to calibrate MWRI brightness temperature data. Wang et al. (2021) quantifies the ice flow acceleration (21.1\%) of Pedersenbreen Glacier during 2016-2017 and unveils the related mechanism. They found that the softened glacier ice due to the air temperature increase $\left(1.5^{\circ} \mathrm{C}\right)$ account for $2.7 \%-30.5 \%$, while other factors account for $69.5 \%-97.3 \%$ of the ice flow acceleration. An et al. (2021) monitored the vertical crustal movements and sea level changes around Greenland using multiple data sources. They found that although the mass loss of Greenland ice sheet can cause considerable global sea level rise, eustatic movements along the coasts of Greenland are quite complex under different mechanisms of sea level changes.

\section{References}

An Jiachun, Zhang Baojun, Ai Songtao, et al. 2021. Evaluation of vertical crustal movements and sea level changes around Greenland from GPS and tide gauge observations. Acta Oceanologica Sinica, 40(1): 4-12

Chen Haihua, Li Lele, Guan Lei. 2021. Cross-calibration of brightness temperature obtained by FY-3B/MWRI using Aqua/AMSR-E data for snow depth retrieval in the Arctic. Acta Oceanologica Sinica, 40(1): 43-53

Inoue J. 2020. Review of forecast skills for weather and sea ice in supporting Arctic navigation. Polar Science, 100523, doi: 10.1016/j.polar.2020.100523

Ji Qing, Ying Liu, Pang Xiaoping, et al. 2021. Characterization of sea ice and its snow cover in the Arctic Pacific Sector during the summer of 
2016. Acta Oceanologica Sinica, 40(1): 33-42

Jung T, Gordon N D, Bauer P, et al. 2016. Advancing polar prediction capabilities on daily to seasonal time scales. Bulletin of the American Meteorological Society, 97(9): 1631-1647, doi: 10.1175/BAMS-D-14-00246.1

Krumpen T, Birrien F, Kauker F, et al. 2020. The MOSAiC ice floe: sediment-laden survivor from the Siberian shelf. The Cryosphere, 14(7): 2173-2187, doi: 10.5194/tc-14-2173-2020

Lawrence H, Bormann N, Sandu I, et al. 2019. Use and impact of Arctic observations in the ECMWF Numerical Weather Prediction system. Quarterly Journal of the Royal Meteorological Society, 145(725): 3432-3454, doi: 10.1002/qj.3628

Lei Ruibo, Xie Hongjie, Wang Jia, et al. 2015. Changes in sea ice conditions along the Arctic Northeast Passage from 1979 to 2012 . Cold Regions Science and Technology, 119: 132-144, doi: 10.1016/j.coldregions.2015.08.004

Mu Longjiang, Liang Xi, Yang Qinghua, et al. 2019. Arctic Ice Ocean Prediction System: evaluating sea-ice forecasts during Xuelong's first transArctic Passage in summer 2017. Journal of Glaciology, 65(253): 813-821, doi: 10.1017/jog.2019.55

Osborne E, Richter-Menge J, Jeffries M. 2018. Arctic report card 2018. (2018.12.14) [2021.12.15] https://www.arctic.noaa.gov/Report-Card

Polyakov I V, Walsh J E, Kwok R. 2012. Recent changes of arctic multiyear sea ice coverage and the likely causes. Bulletin of the American Meteorological Society, 93(2): 145-151, doi: 10.1175/BAMS-D-11-00070.1

Qin Tingting, Jia Tong, Feng Qian, et al. 2021. Sea surface wind speed retrieval from Sentinel-1 HH polarization data using conventional and neural network methods. Acta Oceanologica Sinica, 40(1): 13-21

Rex M, Shupe M, Dethloff K, et al. 2017. The Multidisciplinary drifting Observatory for the Study of Arctic Climate (MOSAiC). In: AGU Fall Meeting 2017. New Orleans: AGU

Wang Zemin, Yan Boya, Ai Songtao, et al. 2021. Quantitative analysis of Arctic ice flow acceleration with increasing temperature. Acta Oceanologica Sinica, 40(1): 22-32 